\title{
ВЛИЯНИЕ ПРИРОДНЫХ ПОЛИСАХАРИДОВ НА ВЫВЕДЕНИЕ ПОЛИЯДЕРНЫХ АРЕНОВ ИЗ МОРСКОЙ СРЕДЫ
}

\author{
(Представил О. Эйзен)
}

Из классов органических веществ, поступающих вместе с недостаточно очищенными стоками или с атмосферными выбросами в водоемы, одним из наиболее распространенных является класс полиядерных аренов (ПА). Представители ПА, многие из которых обладают канцерогенными свойствами $\left[{ }^{1,2}\right]$, идентифицированы и в Балтийском море [3]. В процессе самоочищения ПА кумулируются и частично метаболизируются в элементах экосистемы моря, в частности, в водорослях. Ранее нами установлено, что из видов водорослей, распространенных в Балтийском море, бурые макрофиты способны только кумулировать, а зеленые и харовые и метаболизировать ПА [ $\left.{ }^{4}\right]$. При этом механизм выявленных закономерностей пока не ясен. С другой стороны, известно, что именно бурые водоросли, в том числе и вид Fucus vesiculosus $\left[{ }^{5-7}\right]$, содержат в больших количествах природные полисахариды альгиновую кислоту и ее соли, альгинаты, которые, по данным [ $\left.{ }^{7}\right]$, способны депонировать такие загрязнители, как радионуклиды и ионы тяжелых металлов. Согласно [ $\left.{ }^{7}\right]$, содержание альгиновой кислоты в фукусах, распространенных в Белом и Баренцевом морях, колеблется от 14,4 до $21-27 \%$. Содержание альгината натрия в F. vesiculosus Балтийского моря составляет $20-46 \%$ сухого веса водорослей [ $\left.{ }^{8}\right]$ в зависимости от стадии развития, сезона сбора и условий среды произрастания. Количественное содержание альгиновой кислоты в собранных нами в прибрежной части Финского залива в районе Кабернеэме $F$. vesiculosus, определенное методом обратного титрования [5], составляло в среднем $38 \%$ сухого веса водорослей.

По своей природе альгиновая кислота представляет собой полисахарид и ионообменное вещество $[5,7,9]$. Считают, что она содержится в водорослях в виде смешанной соли. Мономерный состав альгинатов из отечественных водорослей изучен недостаточно. Установлено [7], что альгинаты содержат остатки двух уроновых кислот: $\beta-D$-маннуроновой и $\alpha$ - $L$-гулуроновой, причем содержание последней в них невысокое.

Согласно $\left[{ }^{10}\right]$, молекулы альгиновых кислот включают блоки, состоящие преимущественно из остатков одной уроновой кислоты, а также участки с более или менее регулярным чередованием остатков обеих кислот:

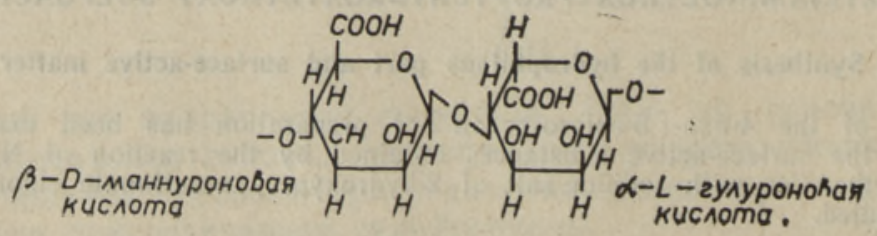


Причем показано ['1], что макромолекула альгиновой кислоты имеет вид цепочки, в которой структурные единицы чередуются между собой, и что одни из них способны гидролизоваться, а другие устойчивы к внешним воздействиям.

Ионообменные свойства альгиновой кислоты связывают с содержанием в ней гулуроновой кислоты [7]. Отмечается также замечательное свойство альгинатов уменьшать отложение радиоактивного стронция в организме человека и животных без изменения усвоения кальция.

Сведений о влиянии полисахаридов на судьбу органических загрязнителей, в том числе ПА, в литературе нами не найдено. Хотя известно, что некоторые природные полимеры способны включать их производные. Так, согласно $\left[{ }^{12}\right]$, одним из механизмов первичной детоксикации продуктов окисления бенз(а) пирена (БП) растениями является их включение в природный биополимер лигнин.

Отсюда вытекает цель настоящего исследования - выяснение роли природных полисахаридов в процессах кумуляции и метаболизма ПА морскими водорослями.

\section{Методика и объекты исследования}

В качестве представителей природных полисахаридов мы выбрали производные альгиновой кислоты - альгинаты, относящиеся к сравнительно простым и устойчивым органическим веществам, содержащимся в больших количествах в бурых водорослях и выделяющимся из них в воду, особенно в прибрежных районах. Использованный в исследовании альгинат натрия выделяли из описанных выше бурых водорослей $F$. vesiculosus по методике $\left[{ }^{5,7}\right]$, несколько нами модифицированной.

Для получения альгината натрия в препаративных целях сырую массу водорослей предварительно промывали и тщательно размельчали, полученную массу выдерживали 45 мин в $2 \%$-ном растворе формалина, а затем 15 суток на воздухе. Такая обработка способствует связыванию пигментов водорослей с образованием белково-целлюлозноформалинового комплекса и получению более чистого раствора альгината [ $]$.

Выделение альгината проходило в пять этапов:

a) навеску сухой массы водорослей (10 г) заливали 500 мл 0,2 н. раствора серной кислоты; смесь перемешивали магнитной мешалкой в течение 15 ч;

б) полученную массу отфильтровывали на воронке Бюхнера (бумажный фильтр «Filtrak 88»); жидкость удаляли, а остаток тщательно промывали дистиллированной водой;

в) остаток заливали 500 мл $1 \%$-ного раствора карбоната натрия; смесь тщательно перемешивали магнитной мешалкой в течение 15 ч при температуре $25-30^{\circ} \mathrm{C}$;

г) полученную густую массу фильтровали, в фильтрат добавляли равное количество $96 \%$-ного этанола;

д) выделившийся белесый остаток альгината натрия отделяли и подсушивали при комнатной температуре.

С БП, типичным представителем канцерогенных ПА, провели две серии опытов.

Первая серия - исследование влияния альгината натрия на скорость окисления канцерогена в модельном растворе (автоокисление). Методика. В реактор со 100 мл раствора хлорида натрия $(5,6$ г/л) в бидистиллированной воде вносили 6 мг альгината натрия. Раствор перемешивали магнитной мешалкой при температуре $20 \pm 2^{\circ}$ до пол- 
ного растворения полисахарида. Затем при непрерывном перемешивании в реактор добавляли 10 мкл раствора БП в этаноле, содержащего $(7,50 \pm 0,24) \cdot 10^{-7}$ г вещества. Полученный раствор перемешивали в течение часа. БП экстрагировали гексаном $(3 \times 30$ мл), предварительно очищенным над активированным углем. Әкстракт выпаривали, сухой остаток растворяли в 2 мл этанола. Количество БП определяли на спектрофотометре «Specord UV-VIS». Параллельно проводили контрольный опыт без внесения альгината с соблюдением всех прочих условий.

Вторая серия - изучение влияния альгината на скорость окисления БП в модельном растворе в присутствии зеленых водорослей Enteromorpha intestinalis, способных поглощать и частично окислять БП. Эти водоросли были собраны в прибрежном районе Меривялья в мае-июне 1984 г. К лабораторным условиям они адаптировались в течение 2-9 дней, а к условиям опыта - в течение 2 дней.

Методика. В реактор с 2000 мл раствора хлорида натрия $(5,6$ г/л) при $\mathrm{pH} 7,5$ (0,02 М фосфатный буфер) вносили, постоянно перемешивая, 20 мг альгината натрия. После полного растворения полисахарида добавляли 0,01 мл раствора БП в этаноле, содержащего $(1,4-3,5) \cdot 10^{-10}$ M вещества - количество, соответствующее возможному уровню загрязнения воды ${ }^{[3]}$. Воздействие бактериальной микрофлоры устраняли добавкой фторида натрия $(0,03$ г/л) [7]. Раствор перемешивали в течение 15 мин, затем в реактор помещали 40 г вымытых водорослей энтероморфы. Световая экспозиция лампой накаливания (освещенность 2600 лк) составляла 45-60 мин. С момента внесения водорослей через определенные промежутки времени из раствора отбирали пробы $(2 \times 100$ мл), которые экстрагировали гексаном $(2 \times 60$ мл). Экстракт обрабатывали безводным сульфатом натрия и выпаривали. Количество БП определяли флюоресцентным методом по квазилинейчатым спектрам люминесценции в н-октане [ $\left.{ }^{14}\right]$. Каждый опыт проводили в двух реакторах одновременно. Параллельно шел контрольный опыт без добавки альгината натрия. После опыта водоросли высушивали, тонко измельчали и экстрагировали бензолом в течение 8 ч в аппарате Сокслета. Әкстракт концентрировался и делился на две части. Одну часть хроматографировали на тонком слое окиси алюминия (по Брокману II). Адсорбционную зону, содержащую БП, элюировали очищенным над активированным углем бензолом ( $3 \times 5$ мл). Бензол выпаривали. Количество БП определяли указанным выше методом. Вторую часть экстракта выпаривали и подвергали хроматографическому анализу на приборе «Perkin-Elmer» серии ЗВ с УФ-детектором и детектором флюоресценции. ПА идентифицировали с помощью УФ-детектора при 360 нм и флюоресцентного детектора фирмы «Kratos» (США) с возбуждением при 315 нм и измерением при 401 нм.

Для выяснения степени удерживания БП клетками бурых водорослей в присутствии энтероморфы был проведен следующий эксперимент. Фукус (сырая масса 40 г) выдерживали в течение 9 ч в 2000 мл раствора хлорида натрия $\left(5,6\right.$ г/л) с БП $\left(\sim 6 \cdot 10^{-10}\right.$ моль) при рН 7,5 (0,02 M фосфатный буфер), освещенности 2600 лк и температуре $20 \pm 2^{\circ}$. Затем эти водоросли переносили в реактор со свежим раствором. Туда же помещали энтероморфу (сырая масса 40 г). Время экспозиции при условиях, указанных ранее, составляло 1ч. Через определенные промежутки времени отбирали параллельные пробы $(2 \times 100$ мл), которые экстрагировали гексаном. Экстракт выпаривали, количество БП определяли флюоресцентным методом. По окончании опыта энтероморфу обрабатывали, как описано выше, и подвергали анализу двумя методами: флюоресцентным и высокоэффективной жидкостной хроматографией (ВЭЖХ). 


\section{Результаты и их обсуждение}

Результаты опытов первой серии (табл. 1) свидетельствуют о том, что добавка альгината натрия в модельный раствор значительно замедляет интенсивность убыли БП во времени из раствора, т. е затрудняет протекание окислительных и сорбционных процессов в системе. Одним из возможных механизмов такого действия может быть экранирование гидрофобных молекул ПА от окислительных агентов, в данном случае молекул растворенного кислорода. Макромолекулы биополимера, обладающие линейной структурой $\left[{ }^{15}\right]$<smiles>COC1OC(OC2COC2OC2OC2O)O1</smiles>

вероятно, сорбируют молекулы растворенного в воде арена.

Таблица 1

Влияние альгината натрия на скорость автоокисления бенз(а)пирена в водной среде

\begin{tabular}{l|c|c|c}
\hline \multirow{2}{*}{ Система } & \multicolumn{2}{|c|}{ Количество БП, $\mathrm{r} \cdot 10^{-7}, n^{*} \pm \sigma$} & $\begin{array}{c}\text { Убыль БП, \% } \\
\text { (в среднем от } \\
\text { исходного) }\end{array}$ \\
\cline { 1 - 3 } & до экспозиции & после экспозицин & \\
\hline $\begin{array}{l}\text { С добавкой альги- } \\
\text { Бата натрия }\end{array}$ & $7,50 \pm 0,24$ & $3,80 \pm 0,34$ & 49,60 \\
Без добавки & 7,34 & 1,84 & 75,00
\end{tabular}

$n^{*}=3$. Условия опытов см. в тексте.

Заметное влияние альгинат натрия оказывает на степень изменения концентрации БП в растворе в присутствии активных по отношению к ПА зеленых водорослей (рис. 1). Изменение концентрации БП в присутствии энтероморфы с добавкой альгината натрия и без него (рис. 2) описывается формально-кинетическим уравнением второго порядка, однако константы скорости, рассчитанные интегральным методом $\left[{ }^{16}\right]$, различаются $\left((1,14 \pm 0,34) \cdot 10^{6}\right.$ и $(1,59 \pm 0,71) \cdot 10^{6} \mathrm{M}^{-1} \mathrm{c}^{-1}$ соответственно для обеих систем). Анализ баланса количества БП после

Рис. 1. Зависимость степени изменения концентрации бенз(а)пирена от времени: с добавкой $10 \mathrm{mr} / л$ альгината натрня, БП - $1,4 \cdot 10^{-10} M(1)$, без добавки в присутствни Enteromorpha intestinalis, БП - 3,5 $110^{-10} \mathrm{M}$ (2). Сырая масса водорослей 40 г. Условия опытов см. в тексте (здесь и к рис. $2-5)$.

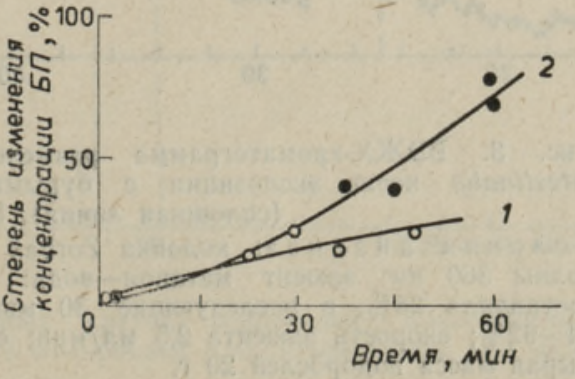




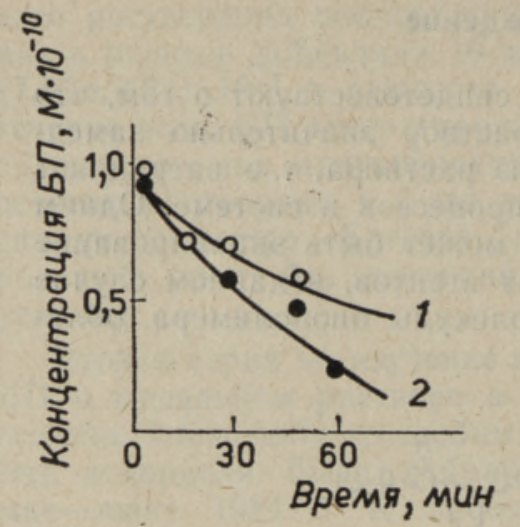

Рис. 2. Кинетика изменения концентрации бенз(а)пирена в присутствни водорослей Enteromorpha intestinalis с добавкой альгината натрия (1) и без добавки: (2).

часового опыта (табл. 2) показывает, что добавка альгината натрия заметно влияет на количество окисленного водорослями энтероморфы канцерогена. Обнаруженный факт может оказаться весьма существенным для экологической практики - в сообществах бурых водорослей с зелеными в результате гибели первых можно ожидать повышения

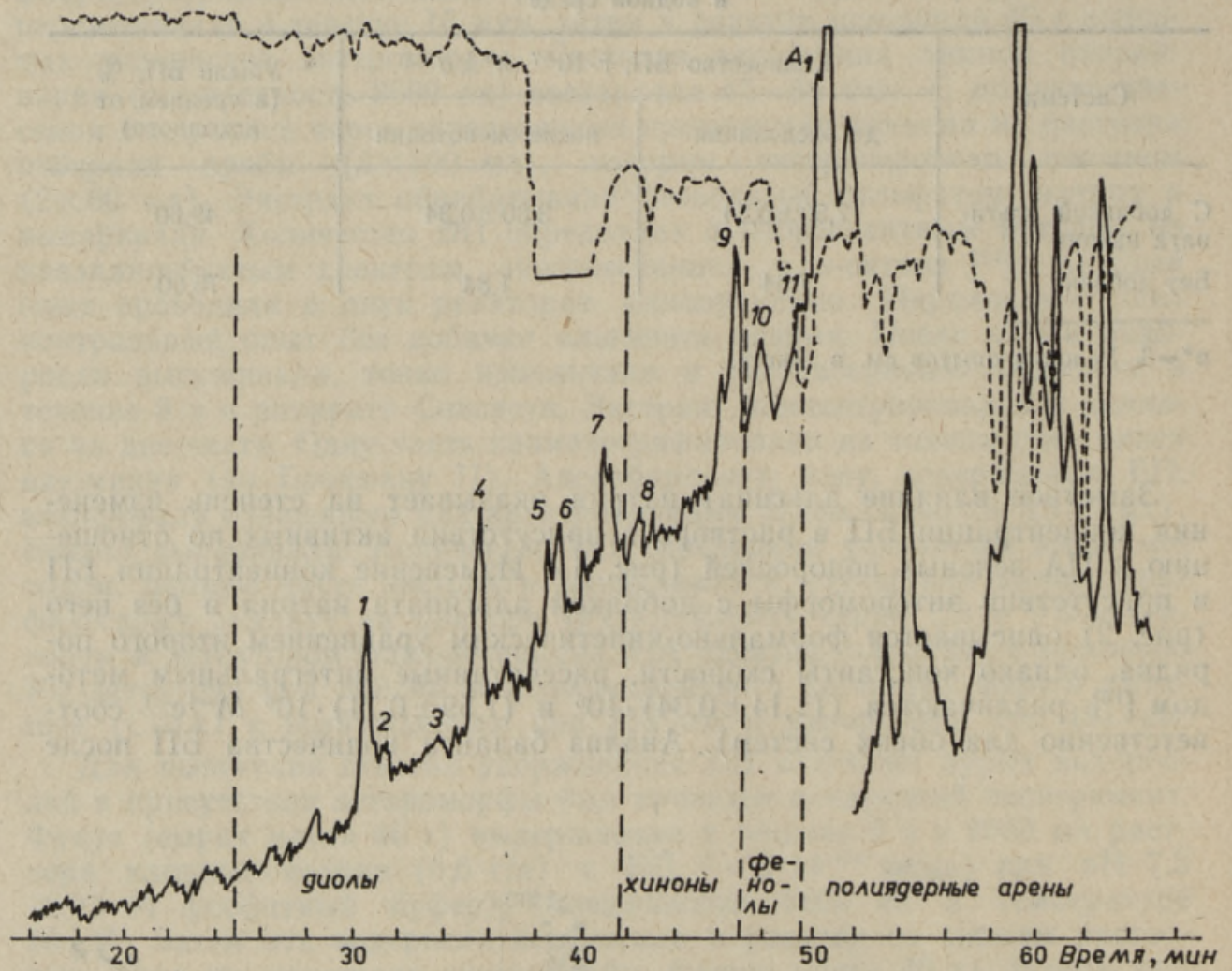

Рис. 3. ВЭЖХ-хроматограмма размельченных клеток водорослей Enterom̄orpha intestinalis после экспозиции с бурыми водорослями: флюоресцентный детектор (сплошная линия), УФ-детектор (пунктир).

Условия анализа: колонка Zorbax C 18, длина 15 см, диаметр 0,6 см; длина волны 360 нм; элюент метанол-вода: концентрация метанола в первые 10 мнн составляла $28 \%$, в последующие 30 мин $-28-84 \%$ и в последние 10 мин $84-92 \%$; скорость элюента 2,5 мл/мин; объем пробы 50 мкл (здесь и на рнс. 4, 5). Сырая масса водорослей 20 г. 


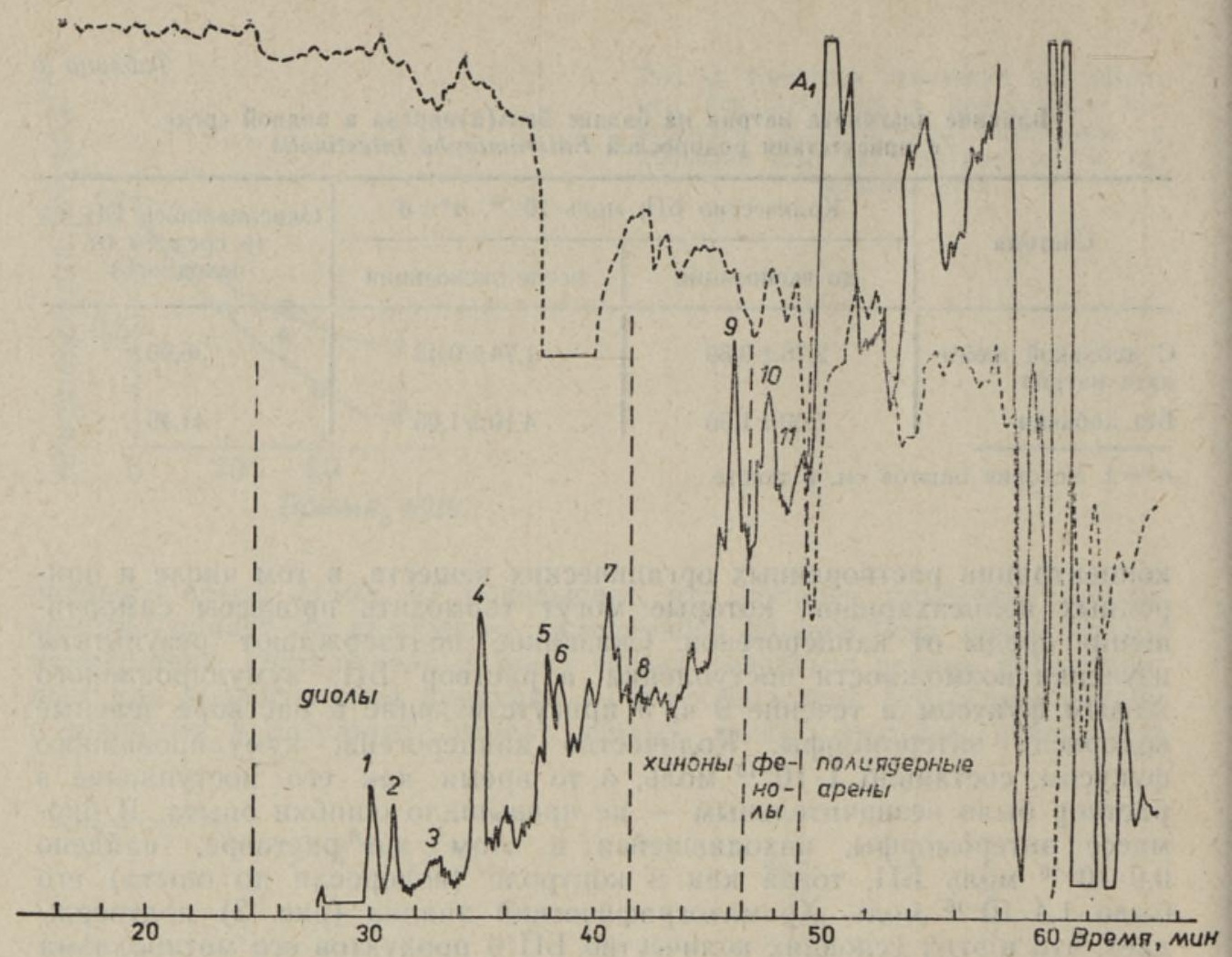

Рнс. 5. ВЭЖХ-хроматограмма размельченных клеток водорослей Enteromorpha intestinalis после экспозиции в растворе, содержащем бенз(а)пирен и альгинат натрия. Сырая масса водорослей 20 г, объем пробы 20 мкл.

в клетках водорослей изменяется незначительно по сравнению с контролем (рис. 4). Таким образом, бурые водоросли (фукус) обладают способностью удерживать кумулированные ПА. Возможно, эти свойства связаны как с отсутствием в фукусе ферментов, обладающих каталитической активностью по отношению к БП, так и с наличием в нем большого количества альгиновой кислоты и ее производных альгинатов.

Сравнение хроматограмм размельченных клеток энтероморфы до и после экспозиции в растворе, содержащем БП и альгинат натрия (рис. 4 и 5 соответственно), свидетельствует, что при общем замедлелии интенсивности окисления БП имеет место метаболический процесс. После опыта в клетках энтероморфы идентифицировано большое количество продуктов метаболического окисления БП: диолов (пики $1-7)$, хинонов (пик $8-1,6$-хинон, пик $9-6,12-$ хинон) и фенолов (пики 10,11); особенно высок выход 6,12-хинона. Следует отметить, что в клетках энтероморфы до опыта содержались БП (пик $\mathrm{A}_{1}$ ) и другие ПА (рис. 4).

\section{Выводы}

1. Интенсивность убыли бенз (а)пирена из воды в присутствии альгината натрия, выделенного из бурых водорослей Fucus vesiculosus, снижается во времени.

2. Добавка альгината натрия замедляет процессы поступления, накопления и окисления бенз(а)пирена в клетках зеленых водорослей Enteromorpha intestinalis.

3. Способность бурых водорослей Fucus vesiculosus кумулировать бенз(а)пирен может быть связана с наличием в них большого количества природных полисахаридов - альгинатов. 
1. Шабад Л. М. О циркуляции канцерогенов в окружающей среде. М., 1973.

2. Suess, M. J. The environmental load and polycyclic aromatic hydrocarbons. Sci. total environment, 1976, 6, 239-250.

3. Kirso, U., Urbas, E., Kuiv, K. Polycyclic arenes in the Baltic waters. - Proc. Acad. Sci. ESSR. Chem., 1981, 30, N 3, 219-223.

4. Irha, N., Kirso, U., Urbas, E., Kukk, H. Oxidation and accumulation of the benzo(a) pyrene in the presence of the Baltic algae. - Acta Hydrochim. et Hydrobiol., 1983, 11, N 4, 449-456.

5. Кизиветтер И. В., Грюнер В. С., Евтушенко В. А. Переработка морских водорослей и других промысловых водных растений. М., 1967.

6. Whistler, R. L., Smart, C. L. Polysaccharide Chemistry. New York, 1953.

7. Радиационная и химическая экология гидробнонтов. Под. ред. Г. Г. Поликарпова. Киев, 1972.

8. Кукк Х. А. Донная растительность Финского залива у берегов СССР. Автореф. канд. дис. Тарту, 1980.

9. Percival, E., McDowell, $R$. H. Chemistry and Enzymology of Marine Algae Polysaccharides. London, New York, 1967.

10. Химический энциклопедический словарь. Под ред. И. Л. Кнунянца. М., 1983.

11. Larsen, B. Biosynthesis of alginate. - In: Xth Intern. Seaweed Symp. Proc. (Göteborg, Sweden, Aug. 11-15, 1980). Ed. T. Levring. Berlin, New York, $1981,7-34$.

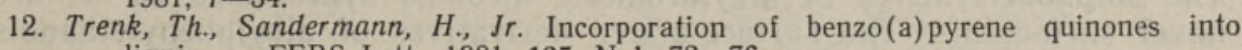
lignin. - FEBS Lett., 1981, 125, N 1, 72-76.

13. Gubergrits, M., Kirso, U., Kuiv, K. Benso(a) püreen Läänemere vees. - ENSV TA Toim. Keem., 1979, 28, N 3, 222-223.

14. Федосеева $\Gamma$. E., Хесина А. Я. Использование квазилинейчатых спектров люминесценции для количественного определения ряда полициклических углеводородов. - Ж. прикл. спектроскопии, 1968, 9, вып. 2, 282-283.

15. Терней А. Современная органическая химия. Ч. ІІ. М., 1981.

16. Лейдлер К. Кинетика органических реакций. М., 1966.
Институт химии
Академии наук Эстонской ССР
Поступила в редакцию
$4 /$ II 1985

\section{Natalja IRHA, Eha URBAS, Uuve KIRSO \\ LOODUSLIKE POLUSAHHARIIDIDE MOJU MITMETUUMALISTE AREENIDE ERALDUMISELE MERE KESKKONNAST}

Artiklis on käsitletud looduslike polüsahhariidide (naatriumalginaadi) mõju kantserogeensete mitmetuumaliste areenide ühe esindaja - benso(a)püreeni (BP) - kontsentratsiooni muutusele vesilahuses. Mudelkatses imiteeriti looduslikke tingimusi. Naatriumalginaat eraldati Läänemeres laialt levinud pruunvetikatest, nimelt mändvetikatest Fucus vesiculosus. Täheldati loodusliku polüsahhariidi inhibeerivat toimet nii $\mathrm{BP}$ autooksüdatsioonile kui ka oksüdeerivale metabolismile rohevetikates Enteromorpha intestinalis. Märgiti, et reaalses merekeskkonnas on vöimalik kantserogeensete areenide lagunemise aeglustumine pruunvetikatest eralduvate polüsahhariidide toimel.

\section{Natalya IRHA, Eha URBAS, Uuve KIRSO}

\section{THE INFLUENCE OF NATURAL POLYSACCHARIDES ON THE REMOVAL OF POLYNUCLEAR ARENES FROM SEA WATER}

In the paper the influence of natural polysaccharides (sodium alginate) on the change in the concentration of benzo(a) pyrene (BP), a typical carcinogenic polynuclear arene, has been studied in aqueous media, in a model experiment under conditions similar to natural ones. Sodium alginate was removed from Fucus vesiculosus, the wide-spread brown alga of the Baltic. An inhibitory effect of natural polysaccharides on both BP autoxidation and oxidative metabolism in the green alga Enteromorpha intestinalis was observed. The possibility of an inhibition of carcinogenic arene degradation was noted in natural sea water under the influence of polysaccharides removed from brown algae. 